cardiac loculus show a thin mucous layer in which only the deeper parts of the tubules are present, and these present extensive and irregular proliferation of their cells, strands of which can be traced down into the underlying submucosa; between these proliferous elements, and in which they appear to be embedded, there is granulation tissue. The submucous coat consists of a dense white fibrous tissue in which the fasciculi of fibrils are well defined, run more or less parallel, have a wavy oblique course, and resemble very closely the fibrous elements seen in dense fibromata and in the atrophic variety of scirrhous carcinomata. Towards the mucous layer this coat is sharply defined; on the other side it penetrates the muscular coat by a series of strands running between the muscular bundles. This dense fibrous tissue shows a great paucity in cells, but in its innermost layers it shows here and there small collections and strands of epithelial cells, many of which can be seen to be directly continuous with similar cells in the mucosa ; and in the remainder of its extent, even where it penetrates between the bundles of the muscular coat, there are to be seen isolated strands and small islands of similar cells between the white fibres, the latter in par ticular being commonly adjacent to some blood-vessel and accompanied by a number of leucocytes. The blood-vessels are few in number and show some thickening of their external coats but no obvious change in their middle or internal coats. The muscular coat does not appear to be increased in thickness; the muscular bundles are separated by strands of dense fibrous tissue penetrating is from the submucosa, which become more and more attenuated in the outer layers and so disappear ; the muscle cells here and there show indications of hyaline transformation but otherwise are normal. The subserous coat is slightly thickened and very occasionally one sees a few epithelial.like cells. The serosa appeared normal. Sections taken from the zone of contraction present similar changes, the mucosa is even thinner, and the folding of the stomach wall is seen to be due to contraction of the fibrous submucosa. Sections from the pyloric portion present appearances very little removed from those of the normal organ. Sections of the lymphatic glands from the gastro-hepatic omentum show here and there small collections of cells, very similar to those described in the submucous coat, situated in the trabeculæ and in the perivascular lymphatics.

Attempting to interpret these appearances there can be no doubt that we have to do with an extensive fibrous hyperplasia commencing in, and chiefly limited to, the submucous coat and involving that coat almost exclusively in its proximal two-thirds, a condition which so far corresponds with Brinton's conception of plastic linitis. The presence of the scanty proliferous epithelial elements in the remains of the mucosa and in the midst of the new formed fibrous tissue of the submucosa demonstrates that the lesion is not merely an inflammatory one in this case but that it is essentially a neoplastic change of a particular type which has its analogue in the so-called atrophic scirrhus met with in the mammary gland.

Leeds.

The Frederick Reynolds Memorial Fund.Substantial progress is reported with regard to the Leeds morement to establish a memorial to the late Mr. Frederick Reynolds of Leeds and Ilkley, who had so many friends not only in the medical profession and among pharmacists in the country but was so well known and respected by his fellow Yorkshiremen. At a recent meeting of the memorial fund committee it was reported that over $£ 100$ had in the course of a few weeks been paid into the fund at Lloyd's Bank, and there were still many promised contributions to be received. The committee expressed its intention to close the fund at the end of January, 1908. All, therefore, who wish their names to be associated with the memorial are desired to forward their contributions at early convenience. Mr. W. H. Scott, 15, Oakwood-avenue, Roundbay, is the honorary secretary. The committee is negotiating with a view, if possible, to extend the dormitory accommodation at the Arnside summer holiday camp for poor Leeds children, or in other ways to help forward the children's summer holiday movement in a form which will admit of a permanent and distinctive memorial. Some of Mr. Reynolds's cartoon work has appeared in our columns. One sketch in particular, which will be found in THE LANCET, Dec. 3rd, 1904, p. 1583, admirably illustrates a lecture by Mr. Edmund Owen and depicts in a style worthy of Oruikshank the trials 0 : the fifth year student of medicine.

\section{THE TUBERCULIN "OPHTHALMO-REACTION" OF CALMETTE.}

BY J. W. H. EYRE, M.S. DURH., F.R.S. EdiN., BACTERIOLOGIST to GUY'S hOSPITAI;

B. H. WEDD, M.D. LOND.,

ASSISTANT BAC'TERIOLOGIST TO GUY'S HOSPITAL;

$A N D$

A. F. HERTZ, M.D. Oxon., M.R.C.P. LoND,, ASSISTANT PHYGICIAN TO GUY'S HOSPITAX.

DURING the past summer considerable interest has" been aroused, especially abroad, by the publication of certain new methods for the diagnosis of tuberculosis, based upon the reaction of the tuberculous subject to tuberculin applied either to the abraded skin or the uninjured conjunctiva. In view of the importance of the subject we have investigated that method known as the tuberculin "ophthalmo-reaction" of Calmette, and upon the result of our observations have formed a diatinctly favourable opinion of the value of this test in diagnosis. We have tested in all 138 individuals, some on more than one occasion, and of these 63 yielded a positive reaction and 75 remained unaffected. Of the 63 positive cases the majority were unquestionably tuberculous; more important still we have not so far noted a definite reaction in a case in which the absence of tubercle has been conclusively proved. Two cases almost certainly tuberculous failed to give a reaction. One was tested twice, an interval of several weeks elapsing between the two attempts, but no reaction was obtained on either occasion; the patient was under treatment with tuberculin and was improving rapidly at the time the test was applied. The diagnosis of tuberculous periostitis of the orbit was made in this case on the result of an inocula tion experiment upon the guinea-pig. The other, a patient suffering from hæmaturia and enlarged kidney, was tested twice with a week's interval, with negative results. No pyuria was present and tubercle bacilli were not found in the centrifugalised deposit from the urine. The diagnosis was made by the surgeon upon the result of cystoscopic examination (a small ulcer considered to be tuberculous being visible) but no operation has so far been performed to confirm the diagnosis. Of the 75 negative cases 17 were adults apparently healthy ; 12 were cases of a doubtful nature, in which the presence of tubercle was a possibility, though there was no evidence of its existence ; 46 suffered from diseases other than tuberculosis.

Before proceeding to detail our own observations it will be useful to review shortly those already published by certain continental workers.

Von Pirquet, working upon the immunity conferred by Jennerian vaccination, concluded that the appearance of a reaction within 24 hours indicated that the patient had already suffered from vaccinia. Oontinuing his investigations in the direction of tuberculosis immunity he found that if a few drops of diluted "old tuberculin" were placed upon the skin and scarification carried ont in the manner employed in Jennerian vaccination a small papule, which resembled the vaccination pustule, appeared at the point of inoculation. The papule, at first clear red, then dusky red, lasted some eight hours in the case of the tuberculous patient, whilst in the healthy individual such a reaction was only very rarely obtained. Von Pirquet published his observations in May, 1907, and stated, on the basis of 500 tests, that the reaction was positive in almost all cases of clinical tuberculosis among infunts. His later work showed the limitations of this reaction-viz., that a positive result was indicative of present or past, active or cured tubercuious infections, so that a positive reaction could only be relied upon during the first year or 18 months of life, while as older infants often reacted and adults reacted almost always (which accords with the experience of the post-mortem room-namely, that nearly all adults are or have been infected with the tubercle bacillus), it was valueless in childhood and adult life. The best reactions were obtained with scrofalous children and those suffering from bone lesions. Occasionally negative results were obtained in miliary tuberculosis, tuberculous meningitis in its later stages, and in children who were already cachectic. 
Vallée obtained a similar cuti-reaction in animals, the traberculous condition of which had been previously ascertained by subcutaneous injection of tuberculin. He further remarked that the reaction was very severe in those which had simultaneously received a hypodermic injection of tuberculin, was definite in those which had received such injections previously to the instillation of tuberculin, but no difference could be detected between those which had received several injections and those which had only received one. Sicard and Descomps stated that the reaction applied to 27 adults was not obtained with sufficient constancy to make the proceeding a useful one for diagnosis. Dufour came to the same conclusion as the result of a series of observations on 20 children of ages varying from three to 14 years. Other observers also came to the conclusion that owing to its unreliability the practical application of the method to diagnosis was limited. Wolff-Rissner of Vienna confirmed in general von Pirquet's observations ; and, further, during some experiments upon the effect of certain substances upon the conjunctiva of animals found that, among other poisons, a 10 per cent, solution of original tuberculin produced an inflammatory chemosis of the conjunctiva or even a feeble general reaction. Vallée utilised this reaction as a means of diagnosis in cattle, but considered that owing to the pain and severity of the symptoms produced it was unsuitable for use in the human subject.

Calmette amplified and extended these observations and described in June, 1907, a modification of this method, which he designated the tuberculin ophthalmo-reaction, for diagnosing tuberculosis in the human subject. Finding the presence of glycerine in the ordinary preparations of the tuberculin of Koch to have an irritating effect upon the human conjunctiva he precipitated the glycerinated product with alcohol and redissolved the deposit to form a 1 per cent. aqueous solution. He stated that one drop of this solution in the eye of a patient suffering from active tuberculous trouble was followed by a definite reaction which did not occur in the normal individual. The reaction consisted of a congestion of the conjunctiva occurring from three to five hours after the instillation of tuberculin; the membrane became reddened and more or less odematous; lacrymation followed, and after six hours a muco-fibrinous secretion became evident, the maximum effect being produced in from six to ten hours. No pain was produced, but there might be slight smarting. The temperature was unaffected.

Since this announcement many observers, especially in France, have confirmed the general accuracy of Calmette's statements. Calmette himself details a series of 25 cases, 16 of which gave a positive reaction. A definite diagnosis of tuberculosis had been made in all but one of these. The nine negative cases were suffering from a variety of diseases other than tuberculous. In a later communication Calmette states that he has received records of nearly 1000 cases tested, with unanimous testimony to the diagnostic value of the reaction. He points out that it may be obtained when tuberculosis of bones or glands is present without clinical symptoms.

Letulle among other observers has published a series of cases with the following results :-

$$
\text { Cases Certainly Tuberculous. }
$$

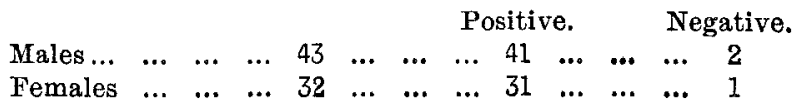

Of the negative cases two were moribund and the diagnosis of tubercle does not appear to have been confirmed it the post-mortem examination in the third.

$$
\begin{aligned}
& \text { Cases Previously Diagnosed as Non-tuberculous. }
\end{aligned}
$$

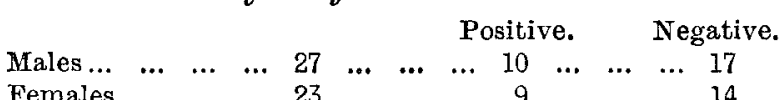

Although the presence or absence of taberculosis does not appear to have been absolutely confirmed in most of his cases this observer regards the presence of a positive reaction of great value in diagnosis.

Grasset and Rumband, in a series of 31 cases, obtained a positive reaction in seven cases certainly tuberculous and five probably tuberculous; a negative result was obtained in 14 non-tuberculous and three doubtful cases; one case considered to be tuberculous gave a negative reaction and one non-tuberculous case a positive reaction. They consider the difficulty of interpretation and the harm which may be done in certain cases by a knowledge of the presence of tuberculosis limits the usefulness of the method. Prouff obtained a positive reaction in 70 cases known to be tuberculous, with only one exception-a patient in a moribund condition. Sicard and Descomps conclude that the ophthalmoreaction is always positive in cases definitely tuberculous and is a much more certain and reliable test than the cutireaction. They, however, record one case definitely tuberculous which gave no reaction a week before death. Dufour remarks that the reaction is the more reliable the younger the subject. Prouff obtained a negative result in six newborn babies of tuberculous mothers; he failed in his attempts to produce a reaction on other mucous membranes. Comby demonstrated the value of the reaction, which he considers a sure and harmless method of diagnosis, on 53 cases, in a certain number of which the diagnosis was confirmed post mortem. Brunetière, Painblan, Sydney Stephenson, and other ophthalmic surgeons have used the reaction for the diagnosis of obscure conditions of the eye, with what they consider highly satisfactory results, although, as the diagnoses necessarily usually lack confirmatory evidence, their conclusions carry but little weight.

Although the opinion of those who have investigated the reaction appears almost unanimous as to its value, Calmette's tuberculin ophthalmo-reaction usually figures both as judge and jury and also court of appeal, and the presence or absence of tuberculosis does not appear to have been substantiated by the results of other methods of investigation in a sufficient number of cases to enable the unbiassed observer to place implicit reliance upon the recorded results. Also it would seem probable that in a certain number of cases doubt had arisen as to the presence or absence of the reaction, leading to difficulty in interpretation of the results obtained. Accordingly, in selecting our cases for the application of the test we endeavoured to obtain a variety of clinical material in which it was probable that the result recorded by the use of the tuberculin might be controlled and confirmed or disproved by some other method of investigation, such as operation or post-mortem inspection, or by the help of micro. scopical examination of morbid exudates or affected tissues, or by means of cultivation methods. In our own observations we have used that preparation of Calmette's tuberculin which is put upon the market by Poulenc Frères, ${ }^{1}$ the solution being freshly prepared not more than 24 hours before use, strictly according to the directions accompanying the "dry" tuberculin-that is to say, ten drops of sterile distilled water were added with a pipette to the dried powder contained in the small bottle, the rubber stopper replaced, and the contents of the bottle vigorously shaken. In applying the test one drop of the watery suspension of tuberculin was deposited in the lower conjunctival fornix of one of the patient's eyes, near to the caruncle, from the same pipette that was used in preparing the original solution.

Letulle, in describing his results, has noted the fact that the reaction obtained does not always correspond completely with that described by Calmette. He considers as positive any definite redness lasting more than eight hours, and divides his positive results into three grades: (I.) redness only ; (II.) marked redness without exudate ; and (III.) active reaction with muco-purulent secretion. In the first place, it will be noticed that his Class III. alone corresponds with Calmette's original description. Secondly, Class I. is too vague and ill-defined to serve as a clinical guide; moreover, in practice it is only met with as the early stage of Class II., so that in the event of differentiation of the degrees of reaction being considered advisable we would suggest that three classes should be arranged as follows: Olass I., comprising only such cases as those in which the reaction is confined to marked injection and tumefaction of the caruncula and plica semilunaris and some lacrymation. Class II., including cases of marked injection of the vessels of the whole of the bulbar conjunctiva and marked lacrymation, accompanied by the changes in the caruncle mentioned under Class I. Class III., including cases of severe reaction, injection and tumefaction of caruncula and plica similunaris, intense injection and chemosis of the bulbar conjunctiva, accompanied by abundant muco-fibrinous exudation and marked epiphora.

1 London agent: M. Jos. Flach, 16, Water-lane, Great Towerstreet, E.C. 
Like Letulle, we have noted cases of accelerated, delayed, and prolonged reactions, but only once have we observed the occurrence of radiating pains in the frontal region to which he refers. We have, unfortunately, not kept a complete record of the degree of the reaction obtained, but the majority of those cases recorded as positive corresponded to Cilmette's original description-that is to say, Letulle's Class III. We examined our exrly cases whenever possible on several occasions, but we soon found that the reaction rarely appeared before about from five to six hours and was not usually well-marked until about 24 hours after instillation of the tuberculin. The date of onset of the reaction was therefore by no means constant, but it will be seen by reference to the detailed table of cases that a reaction if present could always be observed if the eye was examined and compared with its fellow at the end of 24 hours, and we consider that as a routine measure the diagnosis should be based upon the appearances noted 24 hours after the application of the test. Except for slight irritation and the inconvenience caused by swelling and lacrymation, the subjective symptoms noticed have been triling, even when a very acute conjunctivitis appeared to be present. The reaction usually passes off in four days; sometimes it persists longer, and in a few instances a week or ten days have elapsed before the eye has regained its normal appearance. The only case in which complaint was made of severe pain in the region of the eye was one in which a positive reaction, though obtained, had been delayed. The case was tested a second time after a week's interval, a severe conjunctivitis resulted, lasting for five days, and the patient complained of acute local pain with general malaise and joint pains. Not being an in-patient close observation was impossible, and possibly the symptoms complained of were not entirely the result of the taberculin reaction. A case of pyuria, which when examined with the cystoscope showed what appeared to be well-marked tubercles in the bladder, failed to give a reaction when first tested, but at the second attempt, made six days later, gave a wall-marked reaction. This points to the necessity of repeating the test in suspicious cases which at first fail to react, before definitely excluding tubarculosis. Several of our negative cases have been tested more than once, but the above is the only instance of a second test giving a result which differed from the first.

The general results we have obtained in this investigation may be grouped under diseases of the system affected, and are most conveniently summarised as in the following tab!e :-

Type of subject.

Heathy adults $\ldots \begin{array}{llllll} & \ldots & \ldots & \ldots & \ldots & \ldots\end{array}$ $\begin{array}{lllllllll}\text { Phthisis } & \ldots & \ldots & \ldots & \ldots & \ldots & \ldots & \ldots\end{array}$ Other lung diseases ... Diseases of the nervous system ... ... , , genito-urinary system " " bones and joints ..

, , , skin and glands ...

, " serous membranes ...

Various serous membranes.. , " circulatory system ...

\begin{tabular}{c|c|c}
$\begin{array}{c}\text { Total } \\
\text { number } \\
\text { tested. }\end{array}$ & Positive. & Negative. \\
\hline 17 & 0 & 17 \\
13 & 13 & 0 \\
25 & 5 & 20 \\
8 & 1 & 7 \\
4 & 0 & 4 \\
10 & 7 & 3 \\
21 & 15 & 6 \\
17 & 11 & 6 \\
8 & 8 & 0 \\
15 & 3 & 12
\end{tabular}

The details of the individual cases are shown in the tables which follow. In the first of these it will be noted that two cases of tuberculosis of the skin are recorded as failing to respond to the test. Cinically they appeared to be perfectly cured and the results obtained in these cases and in others still under tuberculin treatment lead us to believe that the ophthalmo-reaction will be of value in indicating when the injections may with safety be discontinued. In this connexion we may remark that the instillation of tuberculin causes movements of the tuberculo-opsonin index similar to those which follow a subcutaneous injection, but as the permeability of the conjunctiva differs in different indi. viduals there is no means of judging the exact dose administered in any given case. However, as a note of warning it will suffice to say that the "negative phase" is usually well marked and sometimes lengthy.

Table of Negative Cases.

Sex. $\mid+\frac{\text { Clinical diagnosis. }}{\text { IIcalthy Adults. }}$

14 males tested once ; 2 males tested three times; and 1 female tested once.

Diseases of Respiratory System.

M. Bronchiectasis.

M.

M.

\section{$\mathbf{M}$.}

M. $\mathrm{F}$ M. M. F. M. F. F.

F.

F.

F.

? Bronchitis.

Bronchitis.

Bronchitis.

Pleural effusion.

Pleurisy.

Pueumonia.

Pneumonia. Fmpyema.

Pneumonia.

$$
\text { " }
$$

Whooping-cough.

$$
\text { , }
$$

Broncho-pneumonia.

Empyema.

Cerebral hæmorrhage.

Cerebro spinal meningitis.

Cerebral abscess.

Cerebral tumour.

? Cerebral tumour.

Epilepsy.

Peripheral neuritis.

Heart failure.

Heart disease.

Hæmaturia.

Pyelitis, complicating pregnancy.

Tuberculous kidney and bladder

Tubereulous kidney. culous.

Osteomyelitis. Arthritis.

Synovitis of knee.

? Senile tubercle, foot.

No evidence of tubercle.

Diseases of Nervous System.

No evidence of tubercle. Postmortem examination; lobar pneumonia.

No evidenee of tubercle.

$$
\begin{array}{ll}
", & , \\
" & ,
\end{array}
$$

No evidence of tubercle. Postmortem examination; pneumo coccus septicæmia.

No evidence of tubercle.

$$
\text { ", " }
$$$$
\text { ", }
$$

No evidence of tubercle. Postmortem examination.

$$
\text { , }
$$

No evidence of tubercle.

No evidence of tubercle. Pneumococcus.

No evidence of tubercle. Postmortem examination ; pneumococcus.

\section{Diseases of Circulatory System.}

No evidence of tubercle.

" " "

Diseases of Genito-urinary System.

\section{Diseases of Bones and Joints.}

No evidence of tubercle. No evidence of tubercle. Bacillus coli alone present in pus.

Cystoscope showed solitary ulcer of bladder. No pyaria; no tubercle bacilli detected.

Tuberculous.
No evidence of tubercle. No evidence of tubercle. Paeumococci present in fluid from joint. No evidence of tubercle in sections of excised synovial membrane.

No evidence of tubercle. Sklagraph negative. 


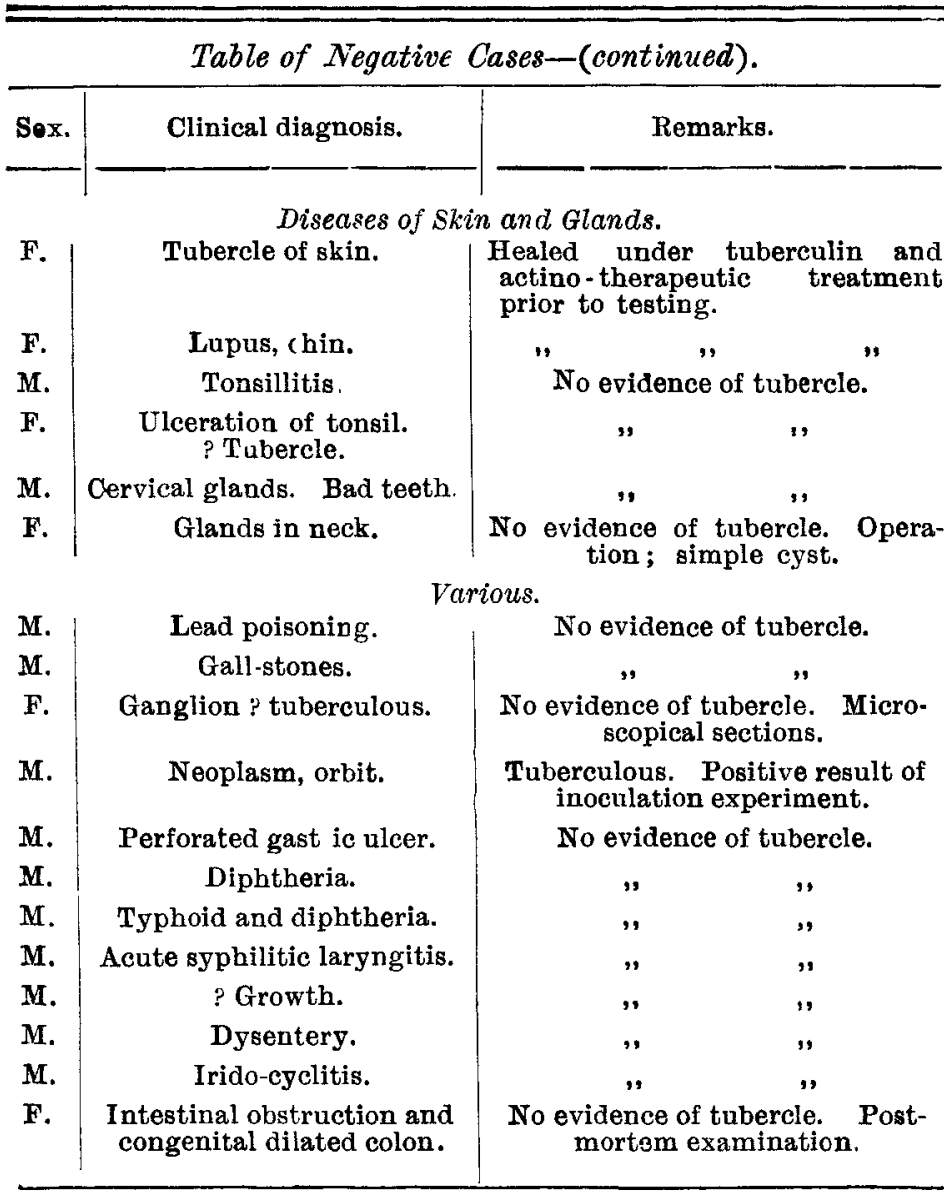

* This patient, tested twice, appears also in the "Positive" table.

Table of Positive Cuses.

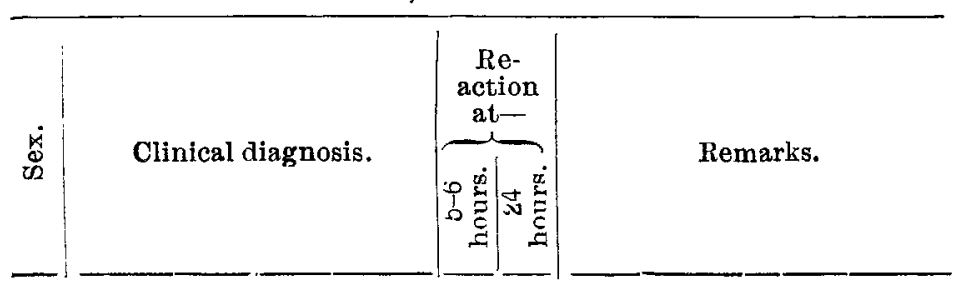

Diseases of the Respiratory System.-Phthisis.

\begin{tabular}{|c|c|c|c|c|c|}
\hline F. & Phthisis. & -1 & + & \multicolumn{2}{|c|}{ Physical signs, \&c. } \\
\hline F. & , & - & + & $"$ & , \\
\hline F. & ," & - & + & ", & ", \\
\hline M. & , & + & + & , &, \\
\hline F. & , & - & + & $"$ & , \\
\hline F. & , & + & + & , & , \\
\hline F. & $" 9$ & + & + & \multicolumn{2}{|c|}{$\begin{array}{l}\text { Physical signs, \&c Post- } \\
\text { mortem examination. }\end{array}$} \\
\hline F. & ", & +1 & + & \multicolumn{2}{|c|}{ Physical signs, \&e. } \\
\hline M. & , & + & + & $"$ & $"$ \\
\hline M. & ", & \pm & + & , &. \\
\hline F. & $"$ & + & + & ", & ," \\
\hline M. & $"$ & + & + & ", & , \\
\hline M. & ," & \pm & + & ", & , \\
\hline
\end{tabular}

Other Diseases of Respiratory System.

F. Tuberculous laryngitis. | $|+|$ Laryngoscopic examination;

M. Pleural effusion. ++ Clinical symptoms.

? Tubercle.

M. $\quad$ M.

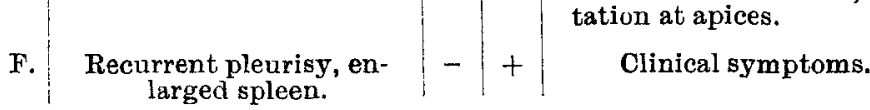

Diseares of Gen 'to-urinary System.

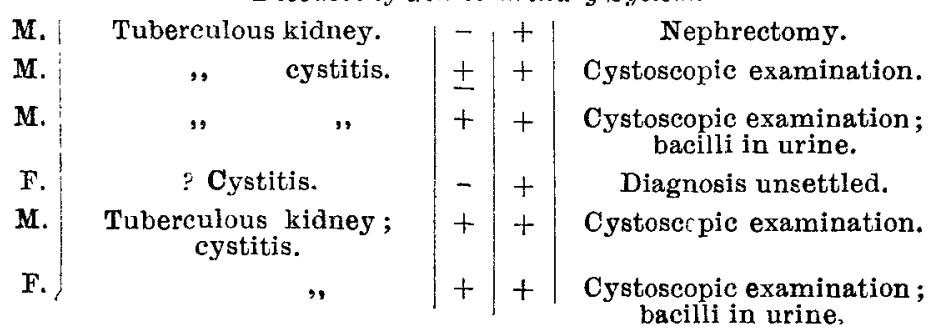

Table of Positive Cuses-(contin"ed).

\begin{tabular}{|c|c|c|c|}
\hline $\begin{array}{l}\dot{x} \\
\dot{w}\end{array}$ & Clinical diagnosis. & 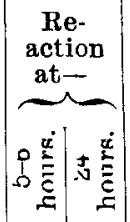 & Remarks. \\
\hline
\end{tabular}

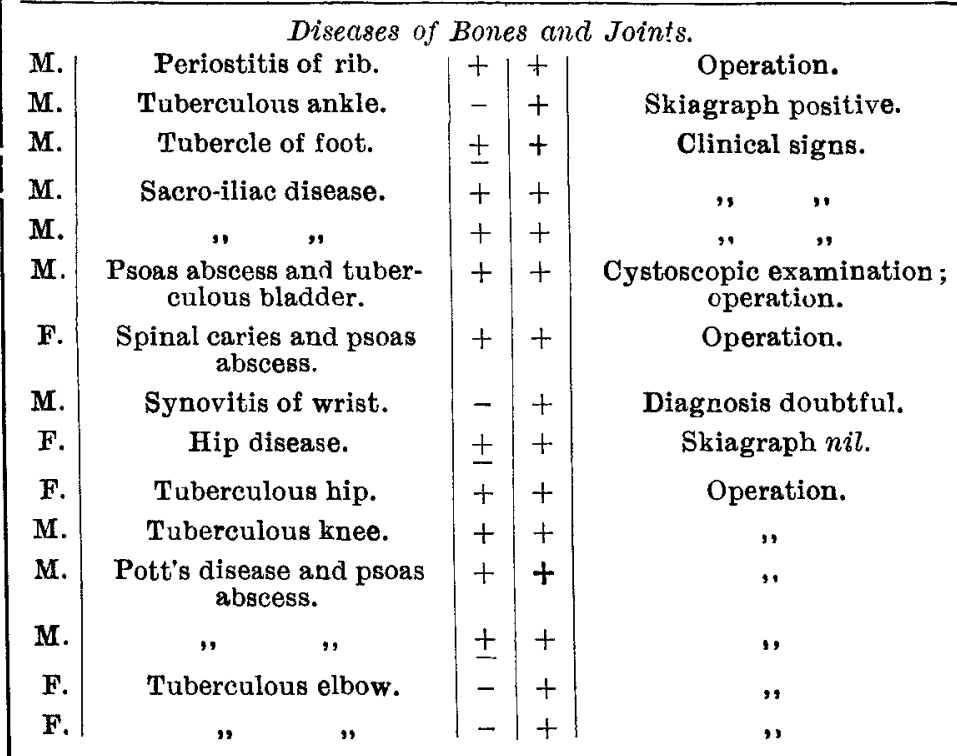

Diseases of Skin and Glands.

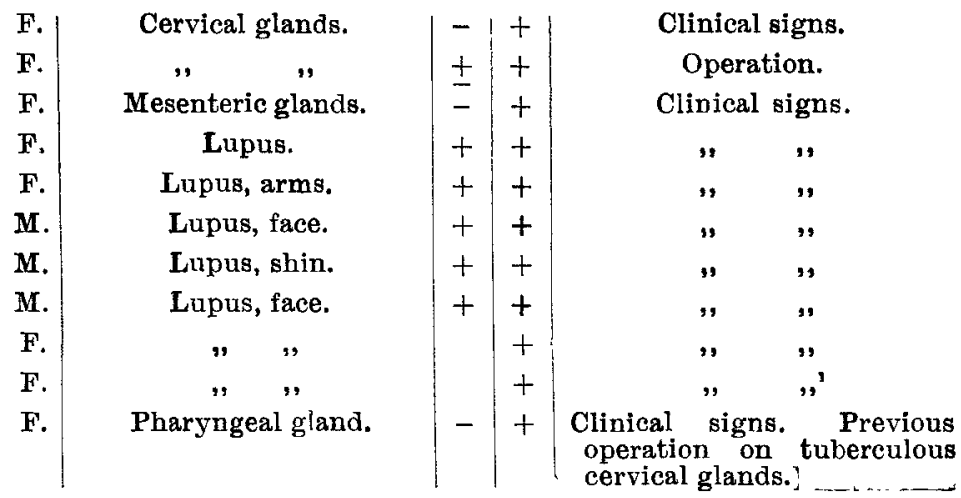

Diseases of Serous Membranes.

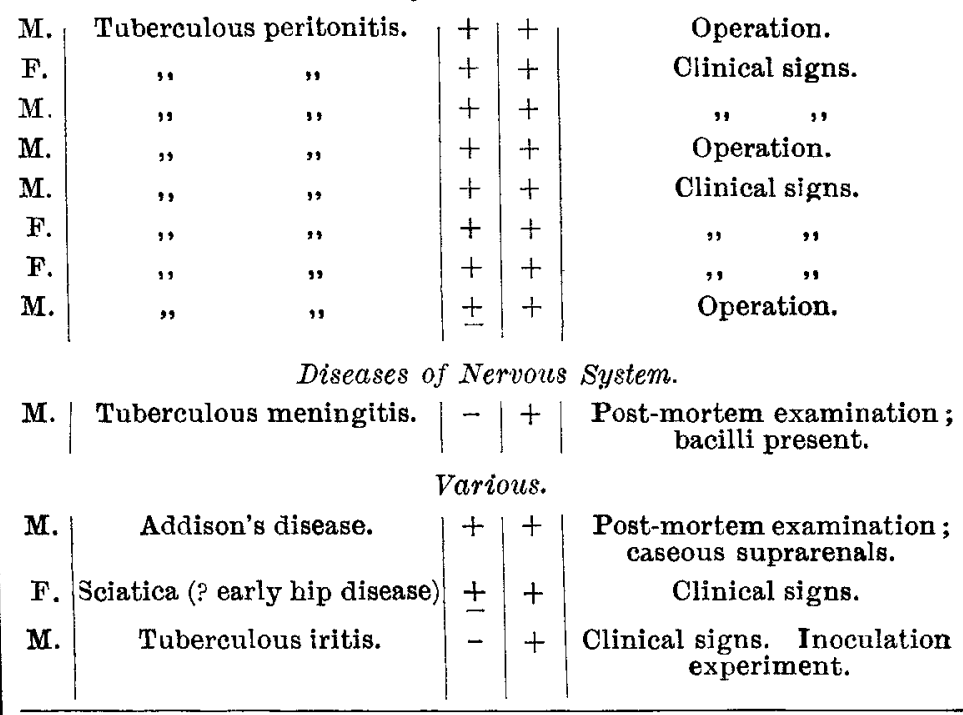

[Since the above tables were prepared we have applied the test to a case of meningitis in a comatose condition. No reaction was observed up to the end of 30 hours, when the patient died. The post-mortem examination demonstrated the existence of general miliary tuberculosis. This experience accords with that of continental observers who state that the reaction cannot be obtained even in undoubtedly tuberculous cases during the last week of life.]

Bibliography.-Arloing: Comptes Rendus de la Société de Biologie, August 2nd, 1907, pp. 1171 and 1215. Aubaret et Lafon : Gazette Hebdomadaire des Sciences Médicales de Bordeaux, August 4th, 1907, p. 361. Brunetiere : L'Opht. Provinciale, August and September, 1907.' A. Calmette : La Presse Médicale, June 19th, 1907, p. 388; Comptes Rendus de l'Académie des Sciences, June 17th (p. 1324) and July $29 t \mathrm{th}$, 1907 (p. 298); La Clinique, August 16th, 1967. Calmette. Breton, Petit, et Painblan: Ia Presse Médicale, July 13th, 1కc7, p. 443. Comby: Bulletin de la Société Médicale des Hôpitaux de 1 mís, July 
18th (p. 766) and August 1st (p. 897), 1907. H Dufour: Bulletin de la Société Médicale des Hôpitaux de Paris, June 27th (p. 627) and July 4th (p. 707), 1907. J. Grasset et L. Rumband : Gazette des Hôpitaux de Paris, August 31st, 1907, p. 1185. J. Lepine: Comptes Rendus de la Société de Biologie. August 2nd, 1907, p. 244. M. Letulle: Bulletin de la Société Médicale des Hôpitaux de Paris, July 4th, 1907, p. 709; Comptes Rendus de la Soclété de Biologie, June 28th, 1907, p. 1168; Presse Médicale, July 3rd, 1967 , p. 41.9. A. Marie et Bourilhet: Comptes Rendus de la Société de Biologie, August 2ad, 1907, p. 281. L. Meille : Rassegna di Terapia, August, 1907, p. 385 . Painblan : L'Opht. Provinciale, August 1907. C. von Pirquet: Wiener Klinische Wochenschrift, Sept. 19th, 1907, p. 1123; Deutsche Medizinische Wochen schrift, May 23rd 'p. 865) and 30th (p. 905), 1907. Prouff: Gazette des Hôntaux de Paris. Bulletin de la Société des Hôpitaux de Paris, June 20th (p. 623) and Bulletin de la Societe des Hôpitaux de Paris, June 20th (p. 623) and
July 4th (p. 696), 1907 A. Slatineanu: Revista Stuuelelor Medicale, July 4th (p. 696), 1907 A. Slatineanu: Revista Stuuelelor Medicale, Oct. 19th, 1907, p. 1038. Vallée: Comptes Rendus de l'Académie des Oct. 19th, 1907, D. 1038. Vallee: Comptes Rendus de PAcademie de Berliner Klinische Wochenschrift, June 3rd, 1907, p. 700.

\section{ביב}

\section{NOTE OF A CASE OF BONE ABSCESS CAUSED BY AN "INTERMEDIATE" BACILLUS ALLIED TO BACILLUS PARATYPHOSUS.}

By F. G. BUShNELL, M.D. Lond., D.P.H. Cantab., PATHOLOGIST TO THE SUSSEX COUNTY HOSPITAL.

F THE patient, aged 41 years, was admitted into the Sussex County Hospital, Brighton, under the care of Mr. R. F. Jowers, on May 25th, 1907, for acute suppurative periostitis. There was a history of a mild attack of "typhoidal" fever five weeks previously when under the care of $\mathrm{Mr}$. F. S. Beachcroft of Petworth. The bone affection came on during convalescence. The first illness was attributed to eating whelks bought off a barrow ten days before the onset of the disease, and this foodstuff also caused sickness and diarrhœa immediately after eating in other members of his family. There was diarrhcea during the first five or six days only; "rose spots" were present and on the twelfth or fourteenth day the Widal reaction to typhoid fever was negative. Pain in the ankle and leg came on during convalescence. On examination there was a tender fluctuating swelling of the size of a bantam's egg on the front and centre of the left tibia. This was incised and 100 cubic centimetres of pus were evacuated from beneath the periosteum. The wound healed rapidly.

Bacteriological report.-Pus from the abscess contained Gram-negative bacilli. Inoculated in broth there was uniform turbidity in 24 hours at $37^{\circ} \mathrm{O}$. due to a motile slender Gram-negative bacillus in pure culture. Gelatin in 24 hours at $22^{\circ} \mathrm{O}$. showed numerous transparent surface colonies with rounded or irregular margins not liquefying the jelly. On Conradi-Drigalski medium small transparent colonies grew. The bacillus measured 0.5 to 1 or $2 \mu$, formed a moist grey growth on agar at $37^{\circ} \mathrm{C}$., formed no spores, no pigment, and possessed no proteolytic powers ; it fermented lævulose, galactose, dextrose, maltose, dulcit, and mannite with gas formation; lactose, raffinose, and sucrose being practically unaffected. Milk was acidified and clotted in 48 hours on two occasions, remaining so for three months; on one cccasion it was rendered alkaline and crotted. No indol was formed, and shake taurocholate neutral red ayar showed no appreciable yellowing. As the typhoid bacillus coagulates milk and renders glucose acid without the formation of gas this is classed generally as paratyphoid (with anomalous variable powers of affecting milk). Sub-groups of the paratyphoid (known also as the hog cholera, paracolon, Gärtner, and intermediate) are formed by the reactions with milk. Thus the ordinary form shows an initial acidity followed by alkalinity in from two to ten days. Sub-group A produces definite persistent acidity but not enough to coagulate milk. These correspond to Buxton's paratyphoid $\beta$ (which resemble the paracolons in culture) and para. typhoid $a$ which is unlike them, though both cause typhoidal symptoms. Ford similarly subdivides the paratyphoid bacilli by the use of xylose and arabinose into the hog cholera, which cannot ferment these carbohydrates, and those parasitic to man (icteroides and paratyphoid), bacillus enteritidis Gärtner and swine dysentery and cattle disease, which can. (Comparative tests were made with paratyphoid $\alpha$ and $\beta 04$ Buxton in the Ralli Laboratory, and with Schottmüller, Gärtner, and others.)
The serum reactions of the patient were significant. His serum was on three occasions negative to bacilli typhi, once during the first illness and twice during the bone affection in 10 per cent. dilutions. On the other hand, he was positive in 1 per cent. dilutions in 30 minutes to Schöttmüller, to paratyphoid a 04 Buxton, and to Gärtner, but negative to bacillus coli. On three occasions the bacillus agglutinated at once with 1 per cent. dilutions of the patient's serum completely.

Remarks.-Though paratyphoid fever is not uncommon in Sussex, a bone abscess following and due to this infection is rare and unrecorded. The sudden onset of the symptoms of poisoning by other members of the family after the eating of the shell-fish is comparable to meat poisoning caused by bacillus enteritidis Gärtner. In this patient the immediate effect was nil but the system was invaded by the bacilli.

Diagnosis would be facilitated by the use of paratyphoid bacilli in serum test. It is notable that Cushing isolated his baciluus $O$ from an abscess following a typhoidal illness and this was erratic in its behaviour to milk as was ours. Castellani also recorded at the meeting of the British Medical Association, 1907, a bacillus which acidified and clotted milk and agglutinated with the serum of a patient suffering from appendicitis from the pus of which it was isolated.

Brighton.

\section{THE AFTER-TREATMENT OF CASES OF SUPRAPUBIC CYSTOTOMY: A NEW AND ECONOMICAL METHOD.}

BY HAMILTON IRVING, M.B., B.S. LOND., M.B., CH B. VICT., M.R.C.S. ENG.,

LATE HOUSE SURGEON, MAYCHESTER ROYAL INFIRMARY; LATE HOUSE SURGEON AND HOUSE PHYSICIAN, EVELIYA HOSPITAL FOR CHILDREN, SOUTHWARK BRIDGE-ROAD, LONDON, S.E.; LATE SENIOR HOL'SE SURGEON, ST. PETER'S HOSPIT'AL FOR STONE, COVENT GARDEN, W.C.

THE patient upon whom suprapubic cystotomy has been performed and who is thereafter buried in the usual bundle of "absorbent" dressings has to pass through a period of great discomfort, and it seems strange that nothing simple and satisfactory has previously been devised which will prevent this discomfort.

With a view to keeping the patient dry pumps of various patterns have been invented which will suck the urine out of the bladder. These are efficient in the early stages of after-treatment, provided that the patient is peaceful and intelligent and can have plenty of atten. tion from his nurses. Their disadvantages are that they are complicated, expensive, and cumbersome, occasionally cause a flood, and limit the movements and therefore the comfort of the patient. Furthermore, the knowledge that he is playing an important part in an apparently com. plicated system of hydraulics is a constant worry to a patient, and I have found that he is always glad to be relieved of such apparatus. There is also the dressing devised by Mr. G. H. Colt, which has evidently answered well in his own hands, and which I found invaluable for sealing off the suprapubic wound in one case where a foul intra-abdominal abscess had to be opened a week after prostatectomy. But my general experience has been that it is messy and difficult to apply, leaks from the beginning, and comes off altogether in three or four days, sometimes leaving the skin excoriated, while it prevents the patient from turning about comfortably in bed. Moreover, the fact that it hermetically seals the wound under a glass case puts it out of court for at least the first fortnight after operation.

During my term of office as house surgeon at St. Peter's Hospital, Covent Garden, I devised an apparatus which keeps the patient dry from the time of operation until the wound is healed, which is simple of application, and which lightens the work of both nurses and surgeon. It has now been used in about 30 cases in the hospital, and the members of the honorary staff are using it in their private practice. It has thus had a fair trial, and I wish to bring it before the notice of the profession. The principle is the simple one of a celluloid cap kept in place over the suprapubic wound by elastic pressure and possessing outlet tubes for the escape of urine. The celluloid porticn is shaped like a straw hat 